\title{
Hans och hennes i svensk tidningstext: frekvens och konstruktion av kön
}

\section{Eva Sundgren}

Frågan om hur män och kvinnor presenteras i media har diskuterats i årtionden, både i Sverige och internationellt (MIK 2016). Det är en viktig fråga, eftersom medier påverkar normer och värderingar. Bussey och Bandura (1999) framhåller att media kan överföra könsstereotyper om kvinnor och män när de presenteras i olika roller, ämnen och olika mycket och skriver (s. 10): " [...] not only are the sexes sharply differentiated in the media, but their roles tend to be even more traditional than is actually the case."

Trots att samhället har blivit mer jämställt finns det fortfarande många skillnader mellan både förekomsten av män och kvinnor och hur män respektive kvinnor skildras. Den internationella Pekingplattformen som bildades 1995 (MIK 2016) är en gemensam internationell FN-överenskommelse om att arbeta för jämställdhet i medier. Sverige och 186 andra stater förbinder sig att "arbeta för att öka representationen av kvinnor i medierna, att aktivt motverka stereotypa könsskildringar, samt att ge kvinnor större tillgång till medier”. Den globala nyhetsstudien GMMP (Global Media Monitoring) utförs vart femte år, och 2010 års undersökning utfördes i 108 länder under en nyhetsdag (Edström, Jacobson \& Lindsten 2012). I Sverige undersöktes åtta dagstidningar, tre radiosändningar, tre TV-sändningar samt de sju största webbnyhetsplatserna. Kvinnor förekom bara i en knapp fjärdedel av det globala nyhetsflödet (24\%), medan motsvarande andel i Sverige var $32 \%$. Andelen kvinnor har i Sverige legat kring $30 \%$ sedan 1990-talet. ${ }^{1}$ Vad kvinnor och män får representera i medierna skiljer sig åt liksom hur en kvinna respektive en man presenteras (Edström, Jacobsen \& Lindsten 2012). Män får oftare uttala sig som experter (i Sverige: $76 \%$ ) eller talespersoner (i Sverige: $73 \%$ ). Kvinnor förekommer i större utsträckning när en personlig erfarenhet ska berättas (i Sverige: $47 \%$ ). Globalt sett är det fyra gånger vanligare att kvinnor presenteras utifrån sin familjesituation än att män gör det. Inom politikområdet är $70 \%$ av nyhetssubjekten i Sverige män.

Min undersökning består av två delar. ${ }^{2}$ Först gjorde jag en kvantitativ undersökning för att jämföra könsfördelningen med nästan 30 års mellanrum. Hur ofta omnämns kvinnor respektive män? Materialet består av alla förekomster av hans och hennes i Göteborgs-Posten (GP) 1994 och 2013 i Språkbankens konkordanser. Jag kompletterade beskrivningen av och diskussionen om könsfördelningen med en kvalitativ undersökning av hur kvinnor och män beskrivs. Hur konstrueras kön? Skildras kvinnor och män på ett könsstereotypt sätt? Jag ansluter mig till Edström, Jacobsen och Lindstens (2012:23) definition av könsstereotyp:

\footnotetext{
${ }^{1}$ Undersökningen GMMP utfördes igen 2015. Kvinnors andel i svenska nyheter ligger fortfarande på samma nivå, omkring $30 \%$, medan andra länder kommer i kapp (Edström \& Jacobsen 2015).

${ }^{2}$ Tack till två anonyma referenter som har lämnat värdefulla förslag till förbättringar av den här artikeln!
} 
Förstelnade föreställningar om vad det innebär att vara man eller kvinna. Könstereotyperna ger ofta uttryck för de drag som anses socialt önskvärda eller typiska hos män och kvinnor; individer som avviker alltför mycket ses med negativa ögon. T ex att det är bra om män är starka och kvinnor är moderliga.

Metoden för den kvalitativa undersökningen är att studera nominalfraserna som följer efter hans och hennes i GP 1994 och 2013.

\section{Tidigare forskning}

I det följande ger jag exempel både från internationell och svensk forskning om konstruktion av könsstereotyper och kvinnor och män i medier, både vad gäller hur ofta kvinnor respektive män förekommer i medier och hur de framställs.

Genom kritisk diskursanalys visade Gunilla Byrman (2001) hur stereotypiserade föreställningar om manligt och kvinnligt kommer till uttryck i språket. Hon undersökte baksidestexter på filmjölkspaket, där det fanns skämt om Leif och Lena. Skämten delade upp män och kvinnor i förenklade, polariserade kategorier. Exempelvis framställdes kvinnor som svaga, arga och svårbegripliga och män som snåla, ouppfostrade och töntiga.

I en undersökning (Sundgren 2007) läste och bedömde olika studentgrupper på semantiska differentialskalor samt med egna kommentarer grovt transkriberade utdrag ur informella samtalsliknande intervjuer (från inspelningarna för Återbesök $i$ Eskilstuna, Sundgren 2002) med en kvinnlig journalist och en manlig fritidspedagog i samma ålder. I den ena gruppen fick informanterna korrekta uppgifter om vem som var kvinna och man, och den andra gruppen fick motsatta uppgifter och trodde att kvinnan var en man och mannen en kvinna. När grupperna bedömde en man uppfattades han som roligare och tryggare än en kvinna som säger detsamma. Karin, journalist, fick fler negativa kommentarer än Mattias, journalist, t.ex.:

Ointelligent, tjurig och bitter kvinna.

För att vara journalist relativt enkla meningsbyggnader som ibland inte hänger ihop. Hon är förhoppningsvis bättre på skrift än på tal.

Det är så att man blir mörkrädd att en journalist ska prata så dåligt för sig.

Att mannen bedöms som roligare än kvinnan stämmer väl överens med vad Maria Ohlsson visar (1999), nämligen att humor är kopplat till konstruktionen av kön. Hennes undersökning tar avstamp i myten om att kvinnor saknar humor. Normerna för könskonstruktion ser inte likadana ut för kvinnor som för män, och enligt Ohlsson kan skämtande närmast beskrivas som en manlig könskonstituent.

Marie Gustafsson Sendén (2015) beskrev vid den åttonde nordiska konferensen om språk och kön hur he och she förekommer och används i engelskspråkig nyhetstext, närmare bestämt Reuters news messages från 1996 och 1997. För varje belägg av she förekom nio belägg av he. Gustafsson Sendén gjorde också en semantisk analys med hjälp av LSA (latent semantic analysis) och kom fram till att de ord som associeras till she är mer könsstereotypa än de som finns i kontexten kring he. 
Maria Edström (2006) undersökte förekomsten av män och kvinnor i SVT och TV4 ${ }^{3}$ och fann att män fyllde $67 \%$ av det undersökta materialet. Kvinnor och män förekom inom olika områden. I nyhetsprogrammen var det män som uttalade sig om politik och ekonomi, medan kvinnor dominerade inom kultur. Liknande resultat fick Roger Desmond och Anna Danilewicz (2010) när de under en tvåveckorsperiod följde tre lokala nyhetsprogram i nordöstra USA. Kvinnliga reportrar presenterade mer nyheter om "mjuka" ämnen och hälsa, medan manliga reportrar presenterade mer om politik. "We also found that when experts are cited in news stories those experts are more likely to be males" (Desmond \& Danilewicz 2010:827).

Det finns flera studier som visar att män förekommer oftare än kvinnor också i böcker och romaner. Jean M. Twenge, W. Keith Campbell och Brittany Gentle (2012) beskriver en amerikansk studie med ett historiskt perspektiv. Frekvensen av he, him, his och himself jämfördes med frekvensen av she, her, hers och herself. Materialet bestod av nästan 1,2 miljoner böcker 1900-2008 i fulltext på Google Books database. Resultatet är att det fanns 3,5 pronomen med manlig referens för varje pronomen med kvinnlig referens 1900-1945 och 4,5 pronomen med manlig referens för varje pronomen med kvinnlig referens 1946-1967. Antalet pronomen med manlig referens minskade 1968-2008 medan de med kvinnlig referens ökade för att mot slutet av undersökningsperioden finnas ungefär dubbelt så många manliga som kvinnliga. Frekvensen av pronomen korrelerar med kvinnors status i USA mätt med indikatorer som utbildning och förvärvsarbete. Om män nämns mycket mer än kvinnor pekar det enligt Twenge, Campbell och Gentle mot att kvinnor har lägre status.

Lisa Holm (2015 01 15) undersöker relationen mellan ordval och stil i tio romaner skrivna mellan 2000 och 2012. Fyra av författarna är manliga och sex är kvinnliga. Ett delresultat är att pronomenet han (plus honom och hans) utgör $73 \%$ och pronomenet hon (henne, hennes) utgör $27 \%$ av den samlade mängden han- och hon-pronomen i materialet.

Som bakgrund till och jämförelse med min undersökning av nominalfraser kopplade till hans respektive hennes använder jag tre tidigare undersökningar om vilken typ av ord som står i förbindelse med dessa två pronomen, nämligen Jann Scheuer (1995), Joakim Lygner (1997) och Karolina Nilsson (2005). Scheuer använde en insamling av nutida texter (19831992) som gjordes i Danmark under 1990-talet som underlag för Den Danske ordbog. Scheuers sökning på hans och hendes visade semantiska skillnader. Hans följdes oftare än hendes av ord som rörde andlig eller offentlig verksamhet och makt. Hendes följdes oftare än hans av ord som karakteriserade utseende och fysik. Lygners material är Press 95 och ett romanmaterial från 1980-81. Romanmaterialet visar att kvinnan ofta förknippas med sina kroppsdelar. Nilsson analyserade 455 belägg från kulturartiklar i Press 98 . Hennes resultat pekar på att bilden av kvinnan inte är lika stereotyp som i Scheuers material.

\section{Min undersökning av frekvens}

För att undersöka hur ofta kvinnor respektive män omnämns i tidningstext och om det har skett en förändring i tidningstext över tid hämtade jag material från Språkbankens konkordanser (〈http://spraakbanken.gu.se〉) med hjälp av verktyget Korp. Det första året som Göteborgs-Posten (GP) finns inlagd från är 1994, och det senaste året (när jag genomförde

\footnotetext{
${ }^{3}$ Edströms material är hämtat från en vecka i februari 2002, klockan 18-23.
} 
undersökningen 2015) var 2013. De ord jag sökte på var hans och hennes. Tabell 1 visar antalet belägg och andelen per miljon token.

Tabell 1. Antal belägg på hans och hennes i GP 1994 och 2013

\begin{tabular}{|c|c|c|c|c|}
\hline & 1994 & & 2013 & \\
\hline Ians & $\begin{array}{c}\text { Antal belägg } \\
14044\end{array}$ & $\begin{array}{c}\text { Per miljon token } \\
658,4\end{array}$ & $\begin{array}{c}\text { Antal belägg } \\
8935\end{array}$ & $\begin{array}{c}\text { Per miljon token } \\
529,6\end{array}$ \\
\hline Hennes & 5154 & 241,6 & 5233 & 310,2 \\
\hline
\end{tabular}

Av alla hans + hennes var 1994 andelen hans $73 \%$ och andelen hennes $27 \%$, medan motsvarande andel 2013 var $63 \%$ hans och 37 \% hennes. Det fanns alltså 2,7 gånger så många hans som hennes i GP 1994 och 1,7 gånger så många hans som hennes 2013.

Kvinnor förekom mycket mer frekvent i GP 2013 än i GP 1994, men det framgår tydligt att könsrepresentationen i GP 2013 fortfarande var ojämn. Året före, 2012, var andelen hans $64,6 \%$ och andelen hennes $35,4 \%$, och det skulle kunna tolkas som att förekomsten av kvinnor ökar hela tiden. För att se om den hypotesen stämmer räknade jag ut andelen hans respektive hennes i alla övriga årgångar av GP som finns på Språkbanken och tabell 2 visar resultaten. I tabell 2 återfinns också resultaten från de år som jag redan redovisat.

Tabell 2. Andel hans respektive hennes av det totala antalet hans + hennes i GP 1994 samt 2001- 2013

$\begin{array}{ccc}\text { År } & \text { Andel hans } & \text { Andel hennes } \\ 1994 & 73,0 & 27,0 \\ 2001 & 70,3 & 29,7 \\ 2002 & 67,4 & 32,6 \\ 2003 & 66,9 & 33,1 \\ 2004 & 67,6 & 32,4 \\ 2005 & 67,6 & 32,4 \\ 2006 & 66,5 & 33,5 \\ 2007 & 65,4 & 34,6 \\ 2008 & 65,5 & 34,5 \\ 2009 & 63,6 & 36,4 \\ 2010 & 63,0 & 37,0 \\ 2011 & 66,6 & 33,4 \\ 2012 & 64,6 & 35,4 \\ 2013 & 63,0 & 37,0\end{array}$

Som tabell 2 visar har förekomsten av kvinnor mätt i andelen hennes inte ökat för varje år, utan ökningen har gått relativt långsamt; 2010 var andelen hennes densamma som 2013.

För att jämföra med en annan dagstidning valde jag Dagens Nyheter (DN) som också finns på Språkbanken. Könsrepresentationen är ännu ojämnare i DN än i GP. Andelen hennes var i DN 22,0 \% år 1987, 23,9 \% år 2004 och 28,6 \% år 2013.

Det är anmärkningsvärt att könsrepresentationen i svenska dagstidningar fortfarande är så skev. Kvinnor utgör hälften av Sveriges befolkning, men som tidigare forskning visar och min undersökning bekräftar är kvinnor underrepresenterade i medier. Genom ökad medvetenhet kan det ske en förändring gällande representation av kvinnor och män i media. Sannolikt är många av läsarna omedvetna om hur könsfördelningen ser ut. Redaktionerna måste aktivt arbeta med förändring. Göteborgsposten bestämde 2005 att "bli bäst i svensk press på att skildra män och kvinnor ur ett jämställt perspektiv” (Edström, Jacobson \& Lindsten 2012:15). 
Som ett led i arbetet mättes antalet kvinnor och män i text och bild varje dag. Mellan år 2007 och 2008 förbättrade nyhetsredaktionen representationen av kvinnor avsevärt och var 2009 uppe i $39 \%$ kvinnor i text och $47 \%$ kvinnor i bild. Nu har emellertid räkningen av andelen män och kvinnor i text och bild upphört på GP, liksom på Uppsala Nya Tidning, två mediehus som tidigare gick i bräschen för ett jämställt medieutbud (Edström \& Jacobsson 2015:69). Däremot började Expressen sommaren 2015 mäta andelen kvinnor och män, och mätningen har gett resultat; den 3 november 2015 hade Expressen cirka 33 \% kvinnor och 67 \% män i nyhetsflödet (Edström \& Jacobsson 2015:59), vilket i och för sig innebär att det fortfarande finns stor förbättringspotential.

\section{Min undersökning av hur kvinnor och män beskrivs i tidningstext}

Liksom Scheuer (1995), Lygner (1997) och Nilsson (2005) undersöker jag vilka ord som står i förbindelse med hans respektive hennes. Min kategorisering av orden bygger på deras undersökningar (se tabell 3), men liksom Nilsson har jag ingen kategori icke-substantiv, utan studerar de substantiv med eventuella bestämningar som följer efter hans och hennes.

\section{Tabell 3. Kategorisering av ord i tidigare undersökningar}

\begin{tabular}{|c|c|c|}
\hline Scheuer (1995) & Lygner (1997) & Nilsson (2005) \\
\hline Icke-substantiv & Icke-substantivord & \\
\hline Kvinnan som kött- och handelsvara & Kroppsrelaterade ord & Kropp och utseende \\
\hline $\begin{array}{l}\text { Mannen som hegemonisk operatör } \\
\text { Familjen }\end{array}$ & Maktrelaterade ord & Ställning och makt \\
\hline Andra relationer & Relationsrelaterade ord & Relationer \\
\hline Död och avgång & Livsrelaterade ord & Liv och död \\
\hline & Produkt- och produktionsrelaterade ord & Yrkesutövande \\
\hline & Själsrelaterade ord & Idéer och ideal \\
\hline & & Namn på verk och rollfigurer \\
\hline & & Egenskaper \\
\hline & & Övriga belägg \\
\hline
\end{tabular}

Metoden var att analysera 250 belägg för varje pronomen och år (GP 1994 och GP 2013) från Språkbankens konkordanser, dvs. 1000 belägg sammanlagt. Jag delade in beläggen i nio betydelsemässiga kategorier samt en tionde rubrik "Övrigt" för de substantiv som var svåra att sortera in under någon av de andra kategorierna. En del kategorier har också delats in i underkategorier. De tio kategorierna är:

\section{Yrkesutövande och aktiviteter}

$\mathrm{A}=$ allmän yrkesverksamhet, t.ex. kontor, nya jobb, ordinarie sekreterarsysslor

$\mathrm{K}=$ kulturell yrkesverksamhet, t.ex. första roman, bildskapande, Searching for Sugar Man

$\mathrm{S}=$ sport, t.ex. 50:e A-kamp, passning, resultat

$\ddot{O}=$ övrigt, t.ex. kursverksamhet, narkotikahandel, egna undersökningar

\section{Relationer}

$\mathrm{F}=$ familj, t.ex. bror, dotter, pappa

$\mathrm{P}=$ par, t.ex. hustru, make, älskare

$\ddot{O}=$ övrigt, t.ex. kollegor, kompisar, egna partivänner

3. Ställning och makt, t.ex. ledning, namn, status 
4. Liv och död, t.ex. barndom, grav, berättelse

5. Kropp och utseende, t.ex. ansikte, blanka ögon, leende

6. Egenskaper, t.ex. blyghet, styrka, positiva tänkande

7. Hus, hem och ägodelar, t.ex. lägenhet, båt, tre hästar

8. Idéer och ideal, t.ex. två idoler, främsta kritik, egna ståndpunkter

9. Känslor, t.ex. depressioner, ilska, lycka

10. Övrigt, t.ex. utpekande, uppmärksamhet, i hennes fall

I tabell 4 redovisas antal belägg för de olika kategorierna. Några av de största skillnaderna mellan vilka betydelsemässiga kategorier som är vanliga för kvinnor respektive män är markerade i tabellen.

Vad gäller Kulturell yrkesverksamhet (1 K) finns färre hennes än hans 2013 som refererar till konstnärlig verksamhet. Skillnaden är större än 1994. Exempel på nominalfraser som följer efter hans 2013 är bästa plattor, deckartrilogi, mest berömda sång, offentliga skulpturer och installationer och värv som författare. Exempel på nominalfraser som följer efter hennes 2013 är dugliga debut, fjolårsroman, gigantiska blå målning och Svanenmärkta soffa Rejoin. I övrigt är skillnaderna inte stora mellan antal belägg som beskriver Yrkesutövande och aktiviteter (1) eller vad nominalfraserna beskriver. I delkategorin Övrigt (1 Ö) finns inte många belägg, men fler efter hans än hennes.

Tabell 4. Fördelningen av hans och hennes i olika kategorier

\begin{tabular}{|c|c|c|c|c|c|c|c|c|c|c|c|c|c|c|c|c|}
\hline \multirow{4}{*}{$\begin{array}{l}\text { kategori } \\
1\end{array}$} & \multirow{2}{*}{\multicolumn{4}{|c|}{ hans 1994}} & \multirow{2}{*}{\multicolumn{4}{|c|}{ hennes 1994}} & \multicolumn{4}{|c|}{ hans 2013} & \multicolumn{4}{|c|}{ hennes 2013} \\
\hline & 60 & & & & 57 & & & & 59 & & & & & & & \\
\hline & A & $\mathrm{K}$ & S & Ö & A & K & $S$ & Ö & A & K & S & Ö & A & K & S & Ö \\
\hline & 8 & 38 & 8 & 6 & 15 & 33 & 5 & 4 & 10 & 32 & 9 & 8 & 8 & 21 & 12 & 1 \\
\hline 2 & 55 & & & & 72 & & & & 63 & & & & 69 & & & \\
\hline & $\mathrm{F}$ & $\mathrm{P}$ & & Ö & $\mathrm{F}$ & $\mathrm{P}$ & & Ö & $\mathrm{F}$ & $\mathrm{P}$ & & Ö & $\mathrm{F}$ & $\mathrm{P}$ & & Ö \\
\hline & 19 & 10 & & 27 & 31 & 14 & & 27 & 18 & 15 & & 30 & 36 & 12 & & 21 \\
\hline 3 & 38 & & & & 12 & & & & 49 & & & & 28 & & & \\
\hline 4 & 30 & & & & 33 & & & & 29 & & & & 21 & & & \\
\hline 5 & 12 & & & & 18 & & & & 2 & & & & 20 & & & \\
\hline 6 & 16 & & & & 10 & & & & 10 & & & & 13 & & & \\
\hline 7 & 11 & & & & 13 & & & & 14 & & & & 23 & & & \\
\hline 8 & 9 & & & & 11 & & & & 7 & & & & 6 & & & \\
\hline 9 & 5 & & & & 9 & & & & 5 & & & & 3 & & & \\
\hline 10 & 14 & & & & 15 & & & & 12 & & & & 19 & & & \\
\hline Antal & 250 & & & & 250 & & & & 250 & & & & 250 & & & \\
\hline
\end{tabular}

I kategorin Relationer (2 P) var det enligt Nilsson (2005) tidigare vanligare att kvinnans partner omnämns än att mannens gör det. Mitt material visar inte någon sådan tendens. Däremot finns tydliga skillnader för delkategorin Familj (2 F). Både Scheuer (1995) och Nilsson (2005) visade att barnen är mer hennes än hans. I mitt material följer ord som kan kategoriseras som Familj oftare efter hennes än hans, och 2013 är beläggen dubbelt så många efter hennes än efter hans. Fördelningen inom kategorin Familj för barn respektive föräldrar (plus faroch morföräldrar) framgår av följande uppställning. Antal belägg står inom parentes.

hans 1994 (4): dotter Kristin, dotter Ylva, son, äldste son 
hennes 1994: (6) dotter Sofia Josefina (2), son, svärdotter, tio barn, två ungar hans 2013 (3): barn-barn, egen son, äldsta dotter Gulnara hennes 2013 (8): dotter, dotter Julia, döttrar (2), son (4)

hans 1994 (7): far (4), mor, föräldrar (2) hennes 1994 (17): far (2), farfar (2), farfar Knut Husberg, farmor (2), finska mormor, fosterfar, föräldrar, mamma (2), mor Cissi, mor (och far), pappa (3)

hans 2013 (7): far, farfarsfar, föräldrar (3), mor, ömma moder hennes 2013 (16): far, farmor änkedrottning, fostermamma, föräldrar (2), mamma (3), mor (3), morfar, pappa (2), pappa Erik, svärmor

Både 1994 och 2013 finns det referenser till fler barn som är hennes, men det finns fler belägg på föräldrar (inklusive far- och morföräldrar), och både 1994 och 2013 fördelar sig de beläggen så att det finns fler än dubbelt så många efter hennes.

I kategorin övriga Relationer (2 Ö) framgår det att männen både 1994 och 2013 har fler kollegor och vänner. Se följande uppställning.

hans 1994 (19): flygbladskollega, irländske kollega, jordanske kollega (2), kollega, kollegor (2), kompisar (2), närmaste medarbetare, partikamrater (4), tidigare kompanjon, två kamrater (2), vänner (2)

hennes 1994 (9): 14 klasskompisar, klasskompisar, kollega och mentor, kompisar, manliga vänner, partikamrater, sex kompisar, tonåriga kompisar, träningskompisar

hans 2013 (17): 21-årige kamrat, anfallskollegor, egna partivänner, flera kompisar, kollegor (4), kompis Hannes Hedengren, kumpaner (3), manuskonsult och ovärderliga medarbetare, partivänner, väninna, vänner (2)

hennes 2013 (8): arbetskamrater, klasskompisar, kollegor vid Uppdrag granskning (2), kompisar, rumskompis Nova, studiekamrater, vänner

Vad gäller kategorin Ställning och makt (3) finns det 38 hans-belägg och 12 hennes-belägg 1994, dvs. 3,2 gånger så många hans, och 49 hans-belägg och 28 hennes-belägg 2013, dvs. 1,8 gånger så många hans. Nilsson (2005) hade i denna kategori 14 belägg efter hans och 4 efter hennes. År 2013 förekom alltså fortfarande betydligt fler män än kvinnor med höga positioner i samhället, men andelen kvinnor hade ökat jämfört med 1994 och Nilssons material från 1998. Exempel på ord som finns efter hans men inte efter hennes 2013 är anhängare, egen politiska karriär, makt och styrka, order, regim, tid vid makten och underlydande chefstekniker, ord som visar mannens överordnade ställning.

Det finns många fler belägg i kategorin Kropp och utseende (5) efter hennes än efter hans, både 1994 och 2013, och skillnaden har ökat så att det 2013 inte fanns ett enda belägg efter hans, men 15 efter hennes. I följande uppställning redovisar jag alla belägg som jag har kategoriserat som Kropp och utseende.

hans 1994 (3): axlar, händer, vänliga leende

hennes 1994 (11): ansikte (3), hand, hy, hår, knä, kropp, läppar, rynkor, tänder

hans 2013:- 
hennes 2013 (15): ansikte (2), blanka ögon, bröst, hals, hand (2), huvud, händer, kropp, leende, mun, nyckelben, underliv

I studien av GP 13 följs hennes oftare än hans av ord som karakteriserar utseende och fysik, vilket även är ett mönster som Scheuer (1995) beskriver.

Några skillnader i kategorin Hus, hem och ägodelar (7) är också värda att påpeka. Det fanns ett par fler belägg efter hennes än efter hans 1994, 13 efter hennes och 11 efter hans. Skillnaden var större 2013, eftersom det fanns 23 belägg efter hennes och 14 efter hans. Nilsson (2005) fann betydligt fler belägg för hennes än för hans för de hus- och hemrelaterade substantiven, 12 hennes och 3 hans. Ett av beläggen efter hans i Nilssons studie var vackra bostad, medan ordet hem förekom två gånger efter hennes. I GP 1994 finns belägget hans vackra och välordnade bibliotek, medan tre belägg efter hennes beskriver inredning och möbler, nämligen nattuksbord, stora tavla och mattor. I GP 2013 finns ordet hem en gång efter hans och fyra gånger efter hennes. Efter hans finns också två belägg på bostad, ett hus och ett hus på Fårö. Två belägg i GP 2013 beskriver möbler efter hennes, nämligen soffa och säng, men det finns i GP 2013 inga belägg som beskriver inredning eller möbler efter hans. Andra ord som inte finns efter hans är rum (3 belägg efter hennes 2013), barnvagn och väska.

Sammanfattningsvis visar undersökningen av vilka nominalfraser som följer efter hans och hennes att det finns skillnader mellan hur kvinnor och män beskrivs och vad de får representera både i GP 1994 och i GP 2013. Både 1994 och 2013 finns många fler belägg som visar mannens makt och ställning, men det finns fler kvinnor med makt och ställning representerade i GP 2013 än 1994. Kvinnor presenteras mycket oftare än män utifrån sin familj, och skillnaden är ännu större i mitt material 2013 än 1994. Däremot finns det mer än dubbelt så många kollegor och vänner efter hans än efter hennes både 1994 och 2013. Det finns också en tendens att hennes hem beskrivs mer än hans. Tydligt är att kvinnor beskrivs mer efter utseende än män.

En stor del av skillnaderna mellan hur kvinnor och män skildras i medier grundar sig i föreställningar om kön och i sociala normer och kan ses som könsstereotyper.

\section{Avslutning}

I den kvantitativa delen av min undersökning jämför jag könsfördelningen i GP 1994 med könsfördelningen i GP 2013. Frågan är: Hur ofta omnämns kvinnor respektive män? I den kvalitativa delen var frågan hur kvinnor och män beskrivs i GP 1994 och 2013. Hur konstrueras kön? Skildras kvinnor och män på ett könsstereotypt sätt? Undersökningen visar eller bekräftar att män förekommer mer frekvent än kvinnor i svensk tidningstext och att det också finns könsstereotypa skillnader i hur en kvinna respektive en man presenteras. Representationen av kvinnor har emellertid ökat i GP mellan 1994 och 2013, och inom ett par områden beskrivs kvinnor respektive män mindre könsstereotypt 2013 jämfört med tidigare undersökningar.

Ann-Catrine Edlund, Eva Erson och Karin Milles (2007:143-147) diskuterar mediernas inflytande och refererar till Anja Hirdmans (2001) summering av mediernas inflytande på vår förståelse av vilka vi är och bör vara, hur samhällsskeenden bör förstås som "kvinnligt" eller "manligt". De ställer frågan "Vilka uttalade och outtalade 'rekommendationer' ges till unga 
kvinnor och män genom mediernas framställning av kön?" (Edlund, Erson \& Milles 2007:147) och hävdar att det inom svensk journalistik saknas en könsmedveten policy. Sedan deras bok om språk och kön kom ut har könsmedvetenheten inom svensk journalistik ökat, även om det fortfarande finns mycket att förbättra. De senaste åren finns enligt Edström \& Jacobsson (2015:52-68) flera positiva exempel på jämställdhetsarbete. SVT:s policy för Sverigespegling och likabehandling gäller från och med 2016, och ett av målen är att "Sveriges befolkning ska avspeglas i såväl utbud som i sammansättning av vår personal”. Sveriges Radio har jämn könsfördelning som mål, och exempelvis P1-morgon och Studio 1 har nått en jämnare könsfördelning. P4:s lokala kanaler har numera en kvinnorepresentation på $46 \%$ av antalet medverkande. Ett annat positivt exempel är att TV4 sedan våren 2015 sänder alla matcher från damallsvenskan på TV4 Play; därmed blev kanalen först i världen med att visa samtliga matcher från en damliga i fotboll.

Med den utvecklingshastighet som har presenterats i den här artikeln verkar det emellertid vara långt kvar till ett jämställt samhälle där kvinnor och män representeras lika mycket $\mathrm{i}$ medier och inte beskrivs utifrån stereotyper. Med den här undersökningen vill jag bidra till att öka den språkliga medvetenheten. Många som läser dagstidningar uppfattar antagligen inte underrepresentationen av kvinnor, eftersom vi länge har varit vana vid att män dominerar i medier.

\section{Referenser}

Byrman, Gunilla. 2001. Leif och Lena - divisiv pakethumor. I: Jönsson, Linda m.fl. (red.), Förhandlingar vid Tjugofjärde sammankomsten för svenskans beskrivning Linköping, 22-23 oktober 1999. (Studies in Language and Culture, No. 2. Linköping Electronic Conference Proceedings, No. 6.) [Hämtat 2016-03-15: http://www.ep.liu.se/ecp/006/ hela_G.pdf].

Bussey, Kay \& Bandura, Albert. 1999. Social cognitive theory of gender development and differentiation. I: Psychological Review, 106. S. 676-713.

Desmond, Roger \& Danilewiez, Anna. 2010. Women are on, but not in, the news: Gender roles in local television news. I: Sex Roles, 62. S. 822-829. [Hämtat 2017-02-22: http://link.springer.com/article/10.1007/s11199-009-9686-5].

Edlund, Ann-Catrine, Ersin, Eva \& Milles, Karin. 2007. Språk och kön. Stockholm: Norstedts akademiska förlag.

Edström, Maria. 2006. TV-rummets eliter. Föreställningar om kön och makt $i$ fakta och fiktion. Göteborg: Institutionen för journalistik och masskommunikation, Göteborgs universitet.

Edström, Maria, Jacobson, Maria \& Lindsten, Simone. 2012. Räkna med kvinnor! Sverige. Global Media Monitoring Project 2010. Nationell rapport.

Edström, Maria \& Jacobsson, Josefine. 2015. Räkna med kvinnor. Global Media Monitoring Project 2015. Nationell rapport Sverige [Hämtat 2016-03-08: http://www.alltarmojligt .se/images/aam/publikationer/raknamedkvinnor_2015.pdf].

Gustafsson Sendén, Marie. 2015. "She" and "He" in news media messages. Pronoun use reflects gender stereotypes. I: Magnusson, J., Milles, K. \& Nikolaidou, Z. (red.), Könskonstruktioner och språkförändringar. Rapport från den åttonde nordiska konferensen om språk och kön. S. 91-102.

Hirdman, Anja. 2001. Tilltalande bilder. Genus, sexualitet och publiksyn i Veckorevyn aktuellt. Stockholm: Atlas. 
Holm, Lisa. 2015. Män är viktigare än kvinnor i svenska romaner. I: Svenska Dagbladet, Språkspalten 2015-01-11.

Lygner, Joakim. 1997. Hennes kropp $i$ hans värld. C-uppsats. Institutionen för svenska språket vid Göteborgs universitet.

MIK, 2016: Kvinnor och män i medier. [Hämtat: 2016-04-01: http://statensmedierad.se/larom medier/kallkritikvemvadvarfor/kvinnorochmanimedier.425.html].

Nilsson, Karolina. 2005. Den obegåvade mätressen och den charmfulle fästmannen. Om stereotypa bilder av kvinnor och män i svenska kulturartiklar. (D-uppsats.) Mälardalssvenska. Nr 2. Rapporter från svenska språket IHu, Mälardalens högskola.

Ohlsson, Maria. 1999. Skämt, makt och myter - humor i genusperspektiv. I: Kvinnovetenskaplig tidskrift $1999 \mathrm{nr}$ 2. S. 31-42.

Scheuer, Jann. 1995. Hans hustru og hendes bryster. I: E. V. Larsen \& M. Kunøe (red.), Mфde om Udforskninen af Dansk Sprog. Århus universitet. S. 246-257.

Språkbankens konkordanser [http://spraakbanken.gu.se].

Sundgren, Eva. 2002. Återbesök i Eskilstuna. En undersökning av morfologisk variation och förändring $i$ nutida talspråk. (Skrifter utgivna av Institutionen för nordiska språk vid Uppsala universitet 56.) Uppsala.

Sundgren, Eva. 2007. Stereotypa uppfattningar om kvinnor och män? Ingvar och Ingvor Lind i ny tappning. I: Gunnarsson, B.-L, Entzenberg, S. \& Ohlsson, M. (red.), Språk och kön $i$ nutida och historiskt perspektiv. Studier presenterade vid Den sjätte nordiska konferensen om språk och kön, Uppsala 6-7 oktober 2006. (Skrifter utgivna av Institutionen för nordiska språk vid Uppsala universitet 71.) S. 253-263.

Twenge, Jean M., Campbell, W. Keith \& Gentile, Brittany, 2012: Male and Female Pronoun Use in U.S. Books Reflects Women's Status, 1900-2008. I: Sex Roles, 67. S. 488-493. [Hämtat 2017-02-22: http://link.springer.com/article/10.1007/s11199-012-0194-7]. 